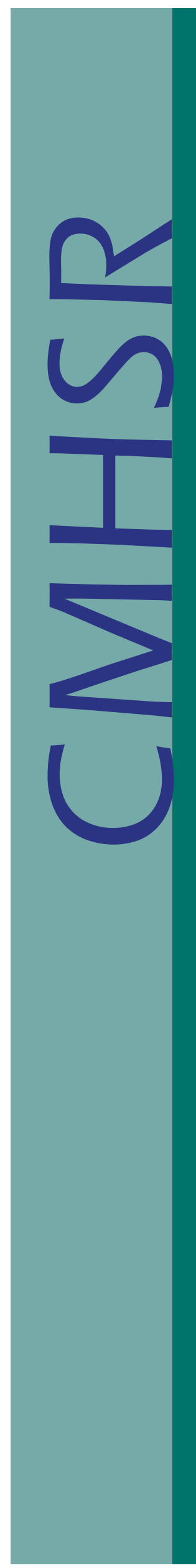

March 2004

Vol 1, Issue 3

\title{
IsSUe
}

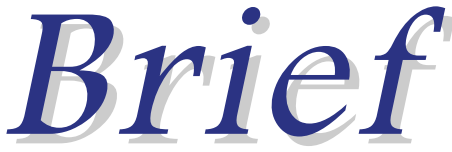

\section{Mental Health and Juvenile Justice Systems: Responding to the Needs of Youth with Mental Health Conditions and Delinquency}

Thomas Grisso, Ph.D., Maryann Davis, Ph.D., and Gina Vincent, Ph.D.

$\mathrm{M}$ any youths who enter the juvenile justice system through delinquency arrests and convictions are in need of mental health services during and after their juvenile justice custody. Research in other states have produced solid evidence that about $70 \%$ of youths in pretrial detention and correctional programs meet criteria for one or more DSM diagnoses. About $15 \%$ to $20 \%$ of those youths are classified as "seriously emotionally disturbed" (SED). CMHSR research using a mental health screening tool in Department of Youth Services (DYS) detention and corrections facilities in Massachusetts found that about the same percent of youths (60\% to $70 \%$ ) manifested symptoms of mental disturbance at clinically significant levels. These youths' mental health needs present several policy questions of significance for Massachusetts Department of Mental Health (DMH).

\section{Competency to Stand Trial}

In the past 10 years, states have experienced the evolution of a new forensic issue in juvenile court: competence to stand trial. In the 1990s, an increasing number of younger youths (10-14) and youths with mental disorders entered the juvenile courts. There is a widespread belief that this happened in part because of cut-backs in public mental health services, resulting in de facto "diversion" of many youths with mental disorders to the juvenile courts. With this increase in juveniles with mental disorders, advocates began to raise the issue of youths' capacities to assist counsel and understand the nature of the proceedings against them (defendants cannot be tried if they do not have these capacities). Assessing competence to stand trial is the responsibility of clinicians in the state's juvenile court clinics (located in all juvenile and family courts in

C 2004 Center for Mental Health Services Research Department of Psychiatry

UMASS. University of Massachusetts Medical School
Massachusetts), and DMH is responsible for funding and managing those clinics. Thus DMH controls policy regarding how juveniles' competence to stand trial evaluations are performed.

Little was known about youths' capacities related to competence to stand trial until a major national study, conducted by faculty at CMHSR and widely publicized nationally, recently discovered that the risk of incompetence to stand trial was significantly greater for youths under 15 years of age than for young adults. ${ }^{1}$ Follow-up work is developing the first assessment tool designed for evaluating youths' competence to stand trial. During the past year, we developed and piloted the tool in conjunction with a number of senior juvenile court clinicians in Massachusetts' DMH-managed juvenile court clinics. It will be available for general use throughout the state's juvenile court clinics in about a year. As that point approaches, it will be important for the Forensic Division of DMH to establish policy regarding the use of the tool. In addition, DMH may wish to engage in collaborative efforts with the Massachusetts Trial Court to educate juvenile court judges and attorneys regarding the issues and assessments of juveniles' competence to stand trial. This responsibility would seem to fall to DMH not only because of its management of the juvenile court clinics, but also because youths with mental disorders constitute the largest group of youths for whom the issue is raised.

\section{Emergency Mental Health Services at Juvenile Justice Intake}

When youths are seen at juvenile court intake or pretrial detention centers soon after arrest, or at reception intake in juvenile corrections, often they present with critical mental health needs that call for an emergency response. These needs include suicide risk, affective and anxiety disorders that offer a heightened risk of anger and danger to other youths and staff, thought 
disturbances, and the risk of toxic reactions associated with recent alcohol/drug use. It is widely acknowledged that meeting these emergency needs requires two primary ingredients: (a) methods to identify mental health needs at intake, and (b) ways to provide emergency mental health services.

Concerning identification, all juvenile detention and corrections facilities should have in place a process for quick, triage screening of youths' emergency mental health needs. During the 1990s, faculty at CMHSR in collaboration with DMH juvenile forensic clinicians, developed a 10-minute, objective, validated mental health screening tool. ${ }^{2}$ It was developed with DMH funding to the CMHSR, private research foundation funding, collaboration with DMH juvenile forensic clinicians, and the cooperation of Massachusetts DYS and its facilities. Currently this instrument, is the most widely used juvenile justice mental health screening tool in the U.S.; it is employed statewide, with every youth admitted to detention or correction facilities, in 26 states (and 6 countries).

Interestingly, this tool-the Massachusetts Youth Screening Instrument (MAYSI)-currently is not used uniformly in Massachusetts DYS facilities. In the interest of serving the mental health needs of Massachusetts youths, and improving public safety, it is strongly recommended that DMH consider the development of interagency policies that encourage the use of this mental health screening instrument-which is free of any financial cost-in DYS detention and intake correction programs. This might occur in conjunction with continued discussions with DYS regarding ways in which DMH and DYS can collaborate to respond to mental health emergency cases that such screening identifies. These are interagency, collaborative policy issues for which many states have made great strides in recent years, offering models for what Massachusetts can achieve with a proper focus on potential solutions.

\section{Long-Term Continuity of Care}

During the 90's, several national longitudinal studies that followed youth with SED (those who were chronic and intensive users of public child mental health and related

Future research at CMHSR will focus on identifying risk factors and risk periods in this population to help policy makers focus their efforts. Research will also address strengths and limitations in the application of evidenced-based delinquency interventions to the child MH population. services) into adulthood raised a red flag; 43-58\% had been arrested by young adulthood. Research conducted at the CMHSR found a 65\% arrest rate among similar DMH adolescents in Massachusetts, with greatest risk of arrest being between the ages of 18 and 20. As researchers at CMHSR have focused on the complexities of the successful transition into adulthood by adolescents with SED in public systems, the high arrest risk findings take on critical importance. Juvenile or adult corrections involvement can interfere with the assumption of adult roles and with good mental health treatment, leading to worsened mental health and deeper involvement in the mental health system. Complicating these matters further is the termination of child services sometime between the ages of 18-21. Research at CMHSR has shown that adolescents with disruptive behavior disorders are often ineligible for adult $\mathrm{MH}$ services. Thus, these youths lose service supports right at the age when they are most at risk of arrest. The loss of services may reduce the likelihood of shifting into positive adult roles, and perhaps indirectly encourage the continuation of criminal activity.

\section{Policy Recommendations}

- It is essential that DMH, DYS, and DOC work together to jointly address the needs of this population.

- Consider collaborative efforts to educate juvenile court judges and attorneys regarding the issues of juveniles' competence to stand trial and its assessment.

- Develop interagency policies that encourage mental health screening in pretrial and correctional facilities.

- Promote continuity of care; delinquency prevention, rehabilitation, and mental health treatment efforts should continue as youth move in and out of DMH, DYS, and DOC, specifically, it might be that once adolescents are deemed eligible for DMH services, they should remain eligible until services are no longer needed, regardless of their age.

\section{References}

1. Grisso, T., Steinberg, L., Woolard, J., Cauffman, E., Chott, E., Graham, S., Lexcen, F., Reppucci, N., \& Schwartz, R. (2003). Juveniles' competence to stand trial: A comparison of adoles cents' and adults' capacities as trial defendants. Law \& Human Behavior, 27(4), 333-363.

2. Grisso, T., Barnum, R., Fletcher, K. E., Cauffman, E., \& Peuschold, D. (2001). Massachusetts youth screening instrument for mental health needs of juvenile justice youths. Journal of the American Academy of Child and Adolescent Psychiatry, 40(5), 541-548.

Visit us on-line at www.umassmed.edu/cmhsr 